\title{
Use of Irradiated Flocculants for Wastewater Treatment
}

\author{
Evgenia Berlinteyger ${ }^{1}$, Tatiana Tyuleneva ${ }^{1, *}$, and Chandara Malik ${ }^{2}$ \\ ${ }^{1}$ T.F. Gorbachev Kuzbass State Technical University, Department of Mineral Processing, 650000 \\ Kemerovo, Russian Federation \\ ${ }^{2}$ Indian Institute of Technology, Mining Engineering Department, 110016 Hauz Khas, New Delhi, \\ India
}

\begin{abstract}
Despite the fact that the problem of petroleum-containing wastewater treatment has existed for decades, it is not completely solved due to the lack of optimal the method of solving the problem from the point of view "cost - results". Therefore, the treatment of petroleumcontaining waste water, giving in the amount of a huge amount of waste, difficult to handle in conventional ways, is an urgent task, especially for small and medium-sized enterprises. The article presents an approach to solving the problem of wastewater treatment by physical and chemical means, which creates the prerequisites for a more efficient treatment of petroleum effluents technically auxiliary materials, such as synthetic flocculants. The technological properties of flocculants with different molecular weight, charge and degree of ionicity are investigated. The dependences of the processes of swelling, adsorption, the rate of petroleum products ' cover formation on the surface of wastewater of a refinery on the type of flocculant are determined. The advantages of this method of treatment in comparison with other methods of improving the purity of wastewater of petroleum refineries are described.
\end{abstract}

\section{Introduction}

Improving the hydroecological state of Kuzbass small rivers is one of the key problems of hydrology, water management and other sectors related to the use of water resources. The water and environmental situation in most of the small rivers is unsatisfactory.

Unfavorable situations are manifested, first of all, in their pollution with waste from various types of economic activities, especially household and industrial wastewater. In recent years, the wastewater of the Yaya Petroleum Refinery poses an increasing threat to small rivers of the Yaya District of Kuzbass. Mass pollution of rivers was the main reason for their loss of fishery value [1].

At the same time, small rivers are the initial link in the formation of water resources of Kuzbass, and their condition largely depends on the quantitative and qualitative state of the Tom river. Therefore, the problem currently observed on the Tom river in Kuzbass is largely a consequence of the situation on small rivers. These rivers are not only a source of

\footnotetext{
*Corresponding author: kta.bua@kuzstu.ru
} 
food for Tom. Their catchments are intensively used in human economic activity for production of various types of products, energy, as well as to meet needs of the population [2].

Petroleum and refined petroleum products are typical environmental pollutants. Petroleum pollution, even in small concentrations, can affect the properties of water, which can cause an environmental disaster.

Currently, there is a low efficiency of environmental activity, as a result there is a violation of the functions of hydrogeological systems, changing their regime and deterioration of water quality [3].

Thus, in modern conditions of environmental management for the Yaya District of Kuzbass, a comprehensive assessment of the hydrogeological situation and the development of a methodology for solving the problem of water management are the most relevant.

\section{Theory of experimental research}

Currently successfully developing microwave chemistry - chemical transformations under the influence of microwave radiation (MWR).

The molecular mass (MM) for modified and unmodified flocculants (Table1), is determined with a capillary viscometer KGV-2 according to the equation of Mark-Houwink for PAA [4]:

$$
[\eta]=6,3 \cdot 10^{-4} M M^{0,8}
$$

It follows from the table data that a result of modification was increasing the molecular weight of polyelectrolytes from 1.2 to 1.8 times; the greatest effect is observed when M 345 is modified by microwave radiation for six seconds at a power of $75 \mathrm{GHz}$ without heating [5].

Table 1. Characteristic viscosity and molecular weight of modified flocculants

\begin{tabular}{|c|c|c|c|}
\hline Modifier & Flocculant & {$[\eta]$} & $\begin{array}{c}\text { Molecular } \\
\text { weight, } \\
\text { million a.m.u. }\end{array}$ \\
\hline without modifier & \multirow{3}{*}{ M 345} & 43.3 & 12.6 \\
\hline PG & & 47.5 & 13.4 \\
\hline MWR & & 55.4 & 15.1 \\
\hline without modifier & \multirow{3}{*}{ M 525} & 33.2 & 10.2 \\
\hline $\mathrm{PG}$ & & 38.4 & 11.5 \\
\hline MWR & & 44.2 & 11.0 \\
\hline without modifier & \multirow{3}{*}{ M 919} & 59.5 & 19.6 \\
\hline $\mathrm{PG}$ & & 63.9 & 20.7 \\
\hline MWR & & 71.1 & 21.3 \\
\hline
\end{tabular}

It was determined that a result of modification M 345 is increasing distances between the ends of macromolecules by 1.4 times, the hydrodynamic volume is by 3.7 times with a slight decreasing flexibility. The obtained data indicate the formation of cross-linked structures of macromolecules due to their chemical modification by propylene glycol molecules and the physical action of microwave radiation [6].

It is known that swelling is an important stage in the preparation of flocculant solutions. Typical dependences of the degree of swelling $(\alpha)$ on time $(t, h)$ are shown in fig. 1 . It shows that the graphic dependencies are asymmetric and have a pronounced maximum. As is established on the basis of graphic dependences, time of swelling for initial and modified flocculants decreases in a row: M $919>$ M $345>$ M 525 at close values of degree of 
swelling. Relative influence of modification on time of swelling of PE settles down in a row of MWR $>$ PG.

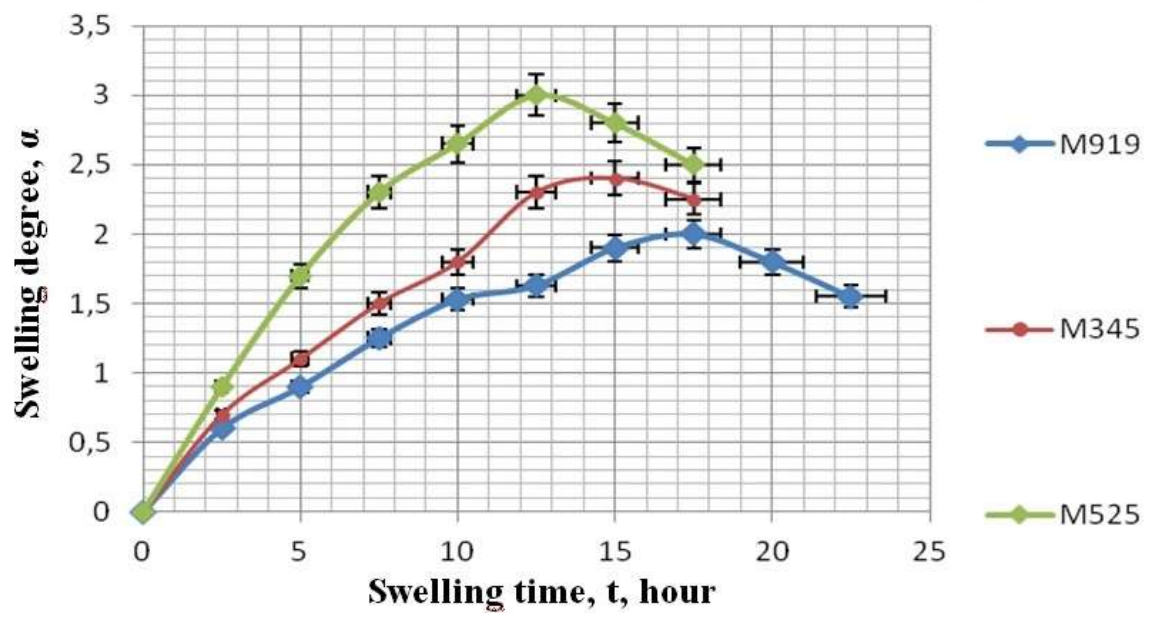

Fig. 1. Curves of flocculants 1-M 919; 2-M 345; 3-M 525` swelling in water at room temperature without mixing.

Analysis of tabular data (Table 2) shows that the greatest time of formation of hydrophobic cover of petroleum products on the surface of wastewater is observed when using highly anionic flocculant M 345, which is modified under MWR. High MM and increased adsorption activity of modified PE lead to rapid destruction of the petroleum emulsion, and dense, and rapidly formed, and stable cover of petroleum products. The greatest demulsifying properties of flocculants, characterizing the density of a cover, are observed in flocculant M 345, which is modified under MWR.

Table 2. Kinetic parameters of petroleum products cover formation for all unmodified and modified flocculants.

\begin{tabular}{|c|c|c|c|}
\hline \multirow{2}{*}{ Flocculant } & Modifier & $\begin{array}{c}\text { The time of petroleum } \\
\text { products' cover } \\
\text { formation, } \mathbf{s}\end{array}$ & $\begin{array}{c}\text { Stability of petroleum } \\
\text { products cover sludge, } \\
\text { visually }\end{array}$ \\
\hline \multirow{3}{*}{ M 345} & without modifier & is not formed & is not formed \\
\cline { 2 - 4 } & PG & 21 & stable \\
\cline { 2 - 4 } & MWR & 10 & stable \\
\hline \multirow{3}{*}{ M 525 } & without modifier & is not formed & is not formed \\
\cline { 2 - 4 } & PG & 29 & is not formed \\
\cline { 2 - 4 } & MWR & 23 & is not formed \\
\hline \multirow{3}{*}{ M 919 } & without modifier & is not formed & stable \\
\cline { 2 - 4 } & PG & 26 & stable \\
\cline { 2 - 4 } & MWR & 13 & \\
\hline
\end{tabular}

Fig. 2 shows the dependence of the volume of petroleum products` cover formed under the the impact of modified nanopolymers on petroleum-containing waste water [7].

As it follows from the figure, that in the range $\mathbf{I}$ there is a maximum release of petroleum components of WW at a dose of $0.2 \%$-flocculant solution of $0.2 \mathrm{ml}(1000 \mathrm{ml}$ of WW). With increasing dose of flocculant, the degree of excretion of the petroleum component of waste waters (range II) with the overcharging of colloidal particles and their stabilization, is reduced. With a further sudden increasing the flocculant consumption, we 
can see the deposition of petroleum components of wastewater again (range III). There is bridging mechanism primarily.

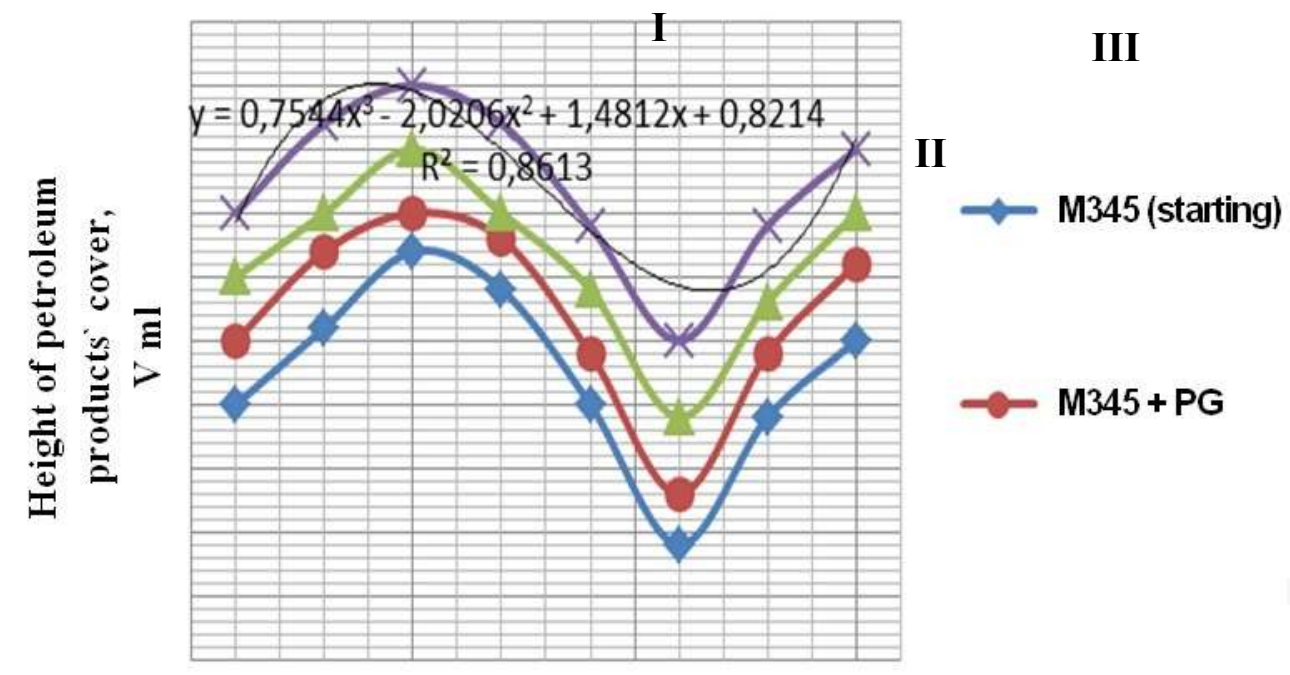

Flocculant consumption, Vf $\mathbf{m l}$

Fig. 2. Dependence of the height of petroleum products` cover from the volume of flocculant at a temperature of $30^{\circ} \mathrm{C}$ and $\mathrm{pH}=6,8$.

The $\mathrm{pH}$ value is an important factor in controlling the process of petroleum-containing wastewater treatment. The colloidal state of the petroleum components and, consequently, the stability of the polydisperse system depends on the $\mathrm{pH}$ value [8].

\section{Results and discussion}

The covers, which are obtained by using flocculants, were deleted by modern floating filters, such as polypropylene fiber, and basalt fiber. Polypropylene fiber and basalt one were used four times, in washing with warm technical water (from 30 to $40^{\circ} \mathrm{C}$ ).

Fig. 3 shows the optimal $\mathrm{pH}$ value of wastewater using flocculant M919, at which the maximum excretion of petroleum components is observed [9], the range of this indicator is from 6.3 to 6.8 .

Also, on the example of flocculant M919 we determined optimal temperature regime with taking into account the volume of the petroleum components' cover from $1000 \mathrm{ml}$ of WW [10]. The temperature varied from 10 to $60^{\circ} \mathrm{C}$. The dependence of the height of petroleum products' cover from the temperature of petroleum-containing wastewater is shown in fig. 4. 


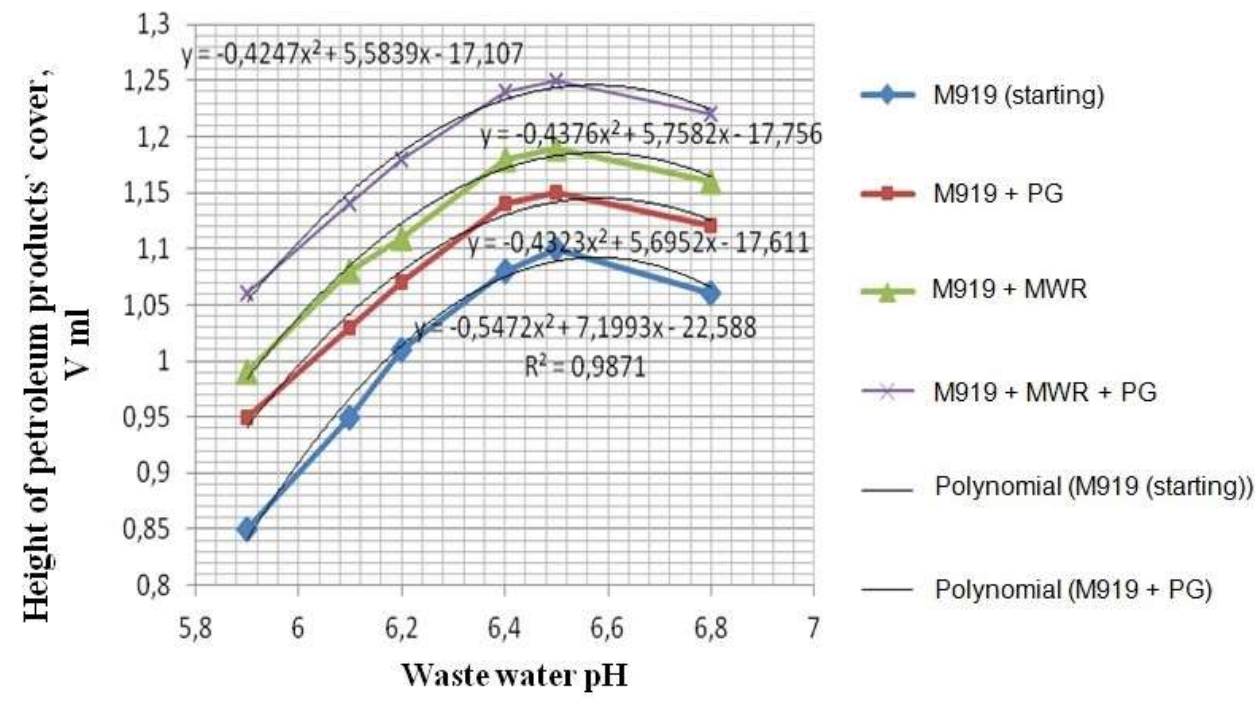

Fig. 3. The dependence of the height of petroleum products` cover from $\mathrm{pH}$ of waste waters at a temperature of $30^{\circ} \mathrm{C}$.

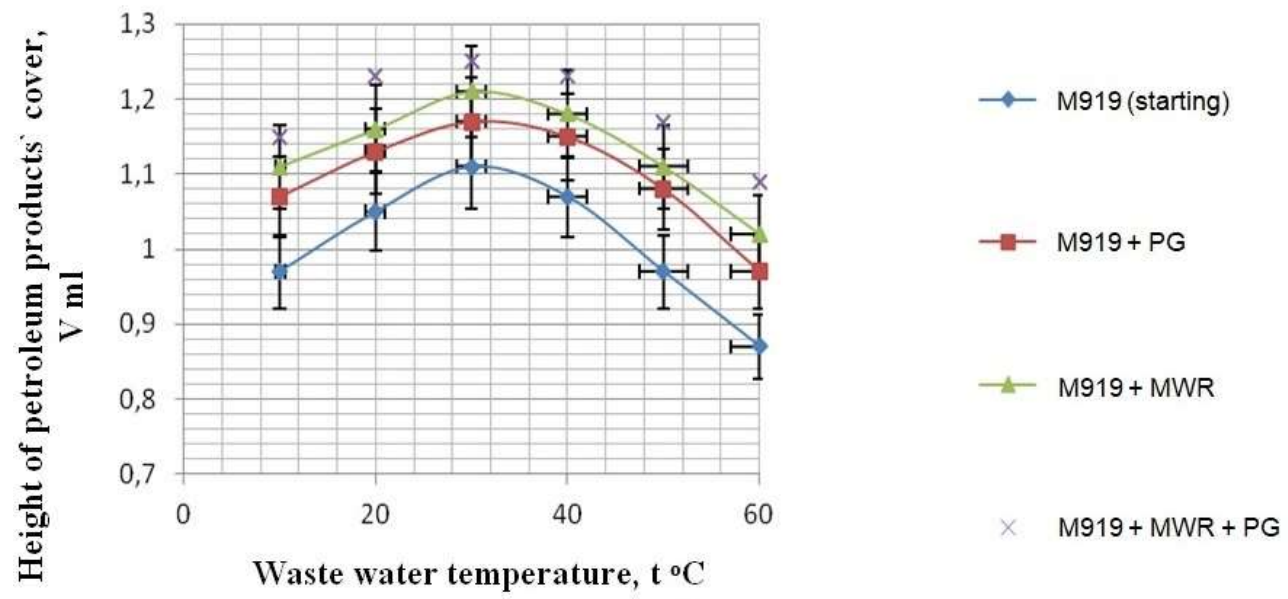

Fig. 4. Dependence of height of petroleum products` cover from the temperature of wastewater at $\mathrm{pH}=6,8$.

As it follows from the analysis of graphic dependences, the optimum temperature of excretion petroleum components of waste waters is $30^{\circ} \mathrm{C}$. At the beginning of heating, increasing the particle velocity causes some agglomeration of petroleum emulsion droplets, and the volume of the petroleum products ' cover increases [11]. Then, from about $30^{\circ} \mathrm{C}$ it also causes disaggregation of emulsion droplets, and the degree of cover formation suddenly decreases.

The completeness of deleting of petroleum products' cover from the surface of the wastewater in the Yaya Petroleum Refinery, we determined using gas-liquid chromatography [12]. We determined the initial amount of petroleum products in $1000 \mathrm{ml}$ of wastewater and the amount of them in $1000 \mathrm{ml}$ of wastewater after using flocculants and floating filters. The test results are presented in table 3 . 
Table 3. Completeness of deleting petroleum products` cover from the surface of the waste water, using flocculants and floating filters

\begin{tabular}{|c|c|c|c|}
\hline $\begin{array}{c}\text { Flocculant } \\
\text { modified } \\
\text { under MWR }\end{array}$ & $\begin{array}{c}\text { Initial content of } \\
\text { petroleum products } \\
\text { in WW, mg/l }\end{array}$ & $\begin{array}{c}\text { Content of petroleum } \\
\text { products after using } \\
\text { polypropylene fiber, mg/l }\end{array}$ & $\begin{array}{c}\text { Content of petroleum } \\
\text { products after using } \\
\text { basalt fiber, } \mathbf{~ m g} / \mathbf{l}\end{array}$ \\
\hline M 345 & 65.468 & 3.440 & 2.039 \\
\hline M 525 & 65.468 & 7.579 & 3.599 \\
\hline M 919 & 65.468 & 4.531 & 3.011 \\
\hline
\end{tabular}

\section{Conclusion}

As it follows from the data (table 3) using modified flocculants and floating filters reduces content of petroleum products in wastewater. The greatest effect at deleting petroleum products from a surface of waste water due to specially organized adsorption is observed for highly anionic flocculant M 345 at its modification under MWR and using basalt fiber as a sorbent. Besides, formed covers can be deleted from the waste water by various ways, such as filtering [13], scrapers [14], basalt fiber and other materials widely used in treatment [15].

In the course of the issue, the scientific and practical bases of technology to reduce the negative impact of economic activity on the chemical content of small rivers in Kuzbass by the method of purification of petroleum products waste water of the Yaya Petroleum Refinery, including the stages of preparating solutions of modified flocculants, the destruction of a stable petroleum emulsion of waste water with using these substances, allowing to reduce the time of formation petroleum products ' cover in 2-3 times, to increase the density of petroleum cover, to increase the rate of adsorption of petroleum products floating on the surface of the filter in 2 times while reducing $99 \%$ of petroleum products concentration in the wastewater. A method for producing anionic flocculants modified under propylene glycol and microwave radiation on the basis of their matrix forms was also developed.

\section{References}

1. T. Tyuleneva, Coal in the 21st Century: Mining, Intelligent Equipment and Environment Protection conference proceedings, 352, 44 (2018)

2. I. Moodley I, C. M. Sheridan, U. Kappelmeyer, A. E. Akcil, Minerals Engineering. 126, 207 (2018)

3. T. Falayi, F. Ntuli, Journal of Industrial and Engineering Chemistry, 20:4, 1285 (2014)

4. W.-L. Jiang, H.-F. Xu. Journal of Chemistry, 2017, 9187436 (2017)

5. T. V. Shevchenko, Yu. V. Ustinova, E. V. Ul'Rikh, V. P. Amelenko, Russian Journal of Applied Chemistry, 83:3, 522 (2010)

6. H. Al-Zoubi, A. Rieger, P. Steinberger, W. Pelz, R. Haseneder, G. Härtel, Separation Science and Technology, 45:14, 2004 (2010)

7. A. Rieger, P. Steinberger, W. Pelz, R. Haseneder, G. Härtel, Desalination and Water Treatment, 6:1-3, 54 (2009)

8. K.K. Kefeni, T. A. M. Msagati, B. B. Mamba. Journal of Cleaner Production, 151, 475 (2017)

9. V. S. Frolov, XVII. International COAL preparation congress, 449, 32 (2013) 
10. S. Mizra, J. F. Richardson. Chem. Eng. Sci., 34, 447 (1979)

11. A. Othman, A. Sulaiman, S. K. Sulaiman, Journal of Water Process Engineering, 15, 31 (2017)

12. V. Masindi, M. W. Gitari, H. Tutu, M. DeBeer, Journal of Water Process Engineering. 15, 2 (2017)

13. H. Al-Zoubi, A. Rieger, P. Steinberger, W. Pelz, R. Haseneder, G. Härtel, Desalination and Water Treatment, 21:1-3, 148 (2010)

14. J. Skousen, C. E. Zipper, A. Rose, P. F. Ziemkiewicz, R. Nairn, L. M. McDonald, R. L. Kleinmann, Mine Water and the Environment, 36:1, 133 (2017)

15. Saleh Al-Muzaini, The Arabian Journal for Science and Engineering, 2:28, 161 (2003) 